\title{
Qualidade Ambiental Urbana
}

\author{
Urban Environmental Quality
}

\section{Calidad Ambiental Urbana}

Sandra Medina Benini

Pós-doutorado pelo PPGARQ-UNESP, bolsista PNPD/Capes, Doutorado em Arquitetura e Urbanismo pela UPM e Doutorado em Geografia pela FCT-UNESP. E-mail: arquiteta.benini@gmail.com

Jeane Aparecida Rombi de Godoy Rosin

Pós-doutoranda pelo PPGARQ-UNESP. Doutorado em Arquitetura e Urbanismo pela UPM. E-mail: jeanerosin@terra.com.br 


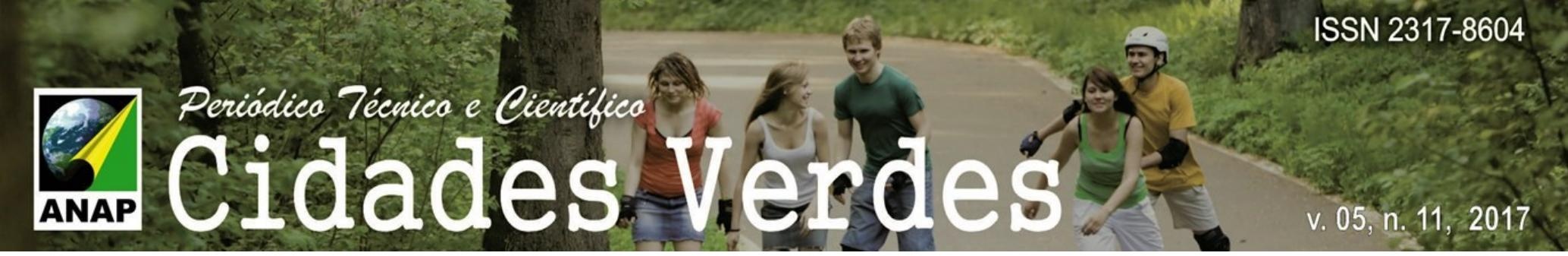

\section{RESUMO}

Este artigo tem por objetivo fazer uma reflexão analítica sobre os conceitos de qualidade de vida e qualidade ambiental, para demonstrar como estes conceitos estão inter-relacionados e subsidiam a construção do conceito de qualidade ambiental urbana. Nas cidades, a busca pela qualidade de vida tem orientado a elaboração e implantação de políticas públicas objetivando o bem-estar coletivo, não somente administradores públicos, mas também pesquisadores de diversas áreas têm encontrado grande dificuldade de definir o que vem a ser qualidade de vida, em razão do caráter subjetivo do conceito, o qual está estritamente relacionado com o atendimento das necessidades humanas, frente ao contexto sociocultural e econômico que o indivíduo esteja inserido. A satisfação das necessidades e desejos humanos é determinada por fatores sociocultural e pelas relações de consumo, e deveriam ser pensados e limitados às partes igualitárias dos bens ambientais, relacionados à capacidade de produção e regeneração da natureza, sem impor riscos ao suporte da vida. Nesta abordagem, passa haver uma correlação entre o conceito de qualidade de vida e o conceito de qualidade ambiental. O conceito de qualidade ambiental incorpora as dimensões materiais e imateriais do meio ambiente, onde os processos vitais das relações ecológicas, da evolução dos ecossistemas naturais e construídos do planeta, da construção/destruição, possibilitando à evolução das paisagens, seja no âmbito externo e interno. Deste modo, pode-se afirmar que qualidade ambiental está intimamente ligada à qualidade de vida, por entender que a vida e meio ambiente são inseparáveis, permitindo uma interação e um equilíbrio entre ambos que se modifica em escala, em tempo e lugar. Essa interação entre qualidade de vida e qualidade ambiental, passa a ser mais evidenciada ao se restringir o objeto de estudo à qualidade ambiental urbana. Por esta razão, depara-se com a problemática em determinar o que é qualidade de vida e o que vem a ser qualidade ambiental urbana, em razão da dificuldade de se estabelecer onde começa uma e onde termina a outra. A delimitação do conceito de qualidade ambiental urbana se reveste de subjetividade ao apontar alguns fatores que interferem na definição da qualidade ambiental urbana como: bemestar, acessibilidade, desenho urbano, uso/ocupação do Solo, saúde física e mental; segurança, organização de classes; realização pessoas, atividades recreativas, realização profissional, etc. Assim, a construção do conceito de qualidade ambiental urbana, pode ser considerando como resultado da inter-relação entre qualidade de vida como a qualidade ambiental, onde o homem, por influência de fatores biológicos, sociais, espaciais, culturais, econômicos, entre outros, é agente passivo ora ativo, na ação ou na omissão, com objetividade ou subjetividade, na produção, reprodução, degradação, destruição do ambiente urbano o qual está inserido.

Palavras-Chave: Sociedade Consumista. Qualidade de Vida. Qualidade Ambiental.

\section{SUMMARY}

This article aims to analyze the concepts of quality of life and environmental quality to demonstrate how these concepts are interrelated and subsidize the construction of the concept of urban environmental quality. In cities, the search for quality of life has guided the elaboration and implementation of public policies aiming at collective well-being, not only public administrators, but also researchers from different areas have found great difficulty in defining what comes to be quality of life, due to the subjective nature of the concept, which is strictly related to the fulfillment of human needs, in view of the socio-cultural and economic context that the individual is inserted. The satisfaction of human needs and desires is determined by sociocultural factors and consumer relations, and should be thought of and limited to the egalitarian parts of environmental goods, related to the capacity for production and regeneration of nature, without imposing risks to the support of life. In this approach, there is a correlation between the concept of quality of life and the concept of environmental quality. The concept of environmental quality incorporates the material and immaterial dimensions of the environment, where the vital processes of ecological relations, the evolution of the natural and constructed ecosystems of the planet, the construction / destruction, making possible the evolution of landscapes, both in the external and internal . In this way, it can be said that environmental quality is closely linked to the quality of life, since it understands that life and environment are inseparable, allowing an interaction and a balance between both that changes in scale, in time and place. This interaction between quality of life and environmental quality becomes more evident when the object of study is restricted to urban environmental quality. For this reason, we are faced with the problem of determining what quality of life is and what is becoming urban environmental quality, due to the difficulty of establishing where one begins and where the other ends. The delimitation of the concept of urban environmental quality is characterized by subjectivity by pointing out some factors that interfere in the definition of urban environmental quality such as: welfare, accessibility, urban design, soil use / occupation, physical and mental health; security, class organization; performing people, recreational activities, professional achievement, etc. Thus, the construction of the concept of urban environmental quality can be considered as a result of the interrelationship between quality of life and environmental quality, whereby man, influenced by biological, social, spatial, cultural and economic factors, among others, is a passive agent now active, in action or omission, with objectivity or subjectivity, in the production, reproduction, degradation, destruction of the urban environment which is inserted.

Keywords: Consumer society. Quality of Life. Environmental Quality. 



\title{
1. CONSIDERAÇÕES SOBRE O CONCEITO DE QUALIDADE DE VIDA
}

Nas cidades a busca pela qualidade de vida tem orientado a elaboração e implantação de políticas públicas visando o bem-estar comum. Entretanto, não somente administradores públicos, mas também pesquisadores de diversas áreas têm encontrado grande dificuldade em definir o que vem a ser qualidade de vida, em razão do caráter subjetivo do conceito, o qual está estritamente relacionado ao atendimento das necessidades humanas, frente ao contexto sociocultural e econômico que o indivíduo esteja inserido.

A Organização Mundial da Saúde (OMS) conceitua qualidade de vida como "a percepção do indivíduo sobre a sua posição na vida, no contexto da cultura e dos sistemas de valores nos quais ele vive, e em relação a seus objetivos, expectativas, padrões e preocupações" (THE WHOQOL GROUP, 1995 p. 1405).

Para Santos e Martins (2002), o conceito de qualidade de vida, pode ser pensado a partir de três aspectos: o primeiro está relacionado com as necessidades do indivíduo (materiais, sociais, culturais, etc); o segundo considera os aspectos individuais e coletivos quanto à distribuição de renda, organização familiar e realização pessoal; e terceiro distingue aspectos objetivos e subjetivos do indivíduo ao determinar qualidade de vida.

Ao relacionar o conceito de qualidade de vida a "satisfação de necessidades", Braga (2002, p. 1) evidencia seu caráter ilimitado, notadamente seus aspectos históricos, espaciais e sociais.

\begin{abstract}
O conceito de qualidade de vida implica tanto a idéia da satisfação de necessidades ou, pelo menos, da possibilidade de sua satisfação, quanto a idéia de falta de privação. Nisso reside a primeira dificuldade na definição do conceito: delimitar quais são as necessidades mínimas a serem satisfeitas ou quais são os bens dos quais o ser humano não pode ser privado. Dado que as necessidades humanas são múltiplas (poderíamos dizer ilimitadas) e variam historicamente, geograficamente e socialmente, esse é um tema em que há pouco consenso. Além disso, a qualidade de vida também possui aspectos subjetivos: a quietude de uma bucólica cidade do interior pode ser encarada tanto como fator de tranqüilidade quanto de monotonia. (BRAGA, 2002, p. 1).
\end{abstract}

Essa proposição de "satisfação de necessidade" enfatizada por Braga (2002) apresenta a ideia de uma sociedade consumista, em que os valores e necessidades básicas se confundem com ícones embutidos pela mídia, na concepção do homem contemporâneo. Complementando, Smith (1980, apud GUIMARÃES, 2005, p. 9) tece apontamentos relacionados ao conceito de qualidade de vida, afirmando que a "satisfação das necessidades e desejos humanos" é determinada por fatores socioculturais e pelas relações de consumo.

Smith (1980), ao tecer considerações sobre o conceito de qualidade de vida, da satisfação das necessidades e desejos humanos, enfatiza as relações interativas de cooperação entre as pessoas, considerando que a 'necessidade é imperativa' e o 'desejo é induzido', sendo determinados por fatores sócio-culturais, onde o grau de 
satisfação encontra-se estreitamente ligado às relações de consumo, serviços, poder sócio-econômico. (apud GUIMARÃES, 2005, p. 9).

O "desejo induzido" citado por Smith (1980) evidencia a sedução e manipulação da vontade dos indivíduos, onde bens e serviços são apresentados como imprescindíveis ao seu bemestar. Para Leff $(2002$, p. 147) este desejo induzido é materializado pela "satisfação/insatisfação, de identificação subjetiva e marginalização cultural por meio do consumo".

\title{
2. A INTER-RELAÇÃO ENTRE O CONCEITO DE QUALIDADE DE VIDA E A QUALIDADE AMBIENTAL
}

Leff $(2002$, p. 148) considera que há uma inter-relação da qualidade de vida com o ambiente em que o indivíduo está inserido e alerta que esta busca incessante pela satisfação das necessidades incide numa demanda por "maior recursos e exerce uma maior pressão sobre o ambiente". A partir dessa visão, a qualidade de vida deveria ser pensada e co-relacionada com a capacidade de suporte do planeta, de modo a reavaliar os valores presentes na sociedade induzida ao consumo desmedido.

\begin{abstract}
A questão da qualidade de vida irrompe no momento em que converge a massificação do consumo e a concentração da abundância, com a deterioração do ambiente, a degradação do valor de uso das mercadorias, o empobrecimento crítico das maiorias e as limitações do Estado para prover os serviços básicos a uma crescente população marginalizada dos circuitos da população e do consumo. (LEFF, 2002, 147).
\end{abstract}

Assim, a "satisfação de necessidades" apontada por Braga e Smith poderia ser ligada e limitada às partes igualitárias dos bens ambientais, relacionados à capacidade de produção e regeneração da natureza, sem impor riscos ao suporte da vida.

Para Cutter (1985) o conceito de qualidade de vida está alicerçado em indicadores: sociais, ambientais e perceptivos. A autora considera que a análise do elemento social e ambiental na interface do bem-estar humano, permite uma avaliação das condições objetivas a partir de uma leitura subjetiva do indivíduo e de suas expectativas em relação ao lugar. Ribeiro e Vargas (2004) esclarecem avaliação da qualidade de vida pode ser feita numa abordagem holística a partir da caracterização do ambiente o qual o indivíduo está inserido.

[...] as avaliações de qualidade de vida devam iniciar-se pela caracterização do meio urbano: a história, o quadro socioeconômico e cultural da população, seus aspectos físicos, recursos disponíveis, elementos poluentes etc. A abordagem holística teria como objetivo de análise a cidade inserida num contexto cultural e subjetivo. (RIBEIRO E VARGAS, 2004, p. 15-16). 


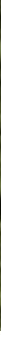

Desta forma os conceitos de qualidade de vida e qualidade ambiental, com dinâmicas próprias dentro de um mesmo sistema, estão atrelados à sustentabilidade sócio-ambiental.

\begin{abstract}
A qualidade de vida está necessariamente conectada com a qualidade do ambiente, e a satisfação das necessidades básicas, com a incorporação de um conjunto de normas ambientais para alcançar um desenvolvimento equilibrado e sustentado (a conservação do potencial produtivo dos ecossistemas, a prevenção diante de desastres naturais, a valorização e preservação da base de recursos naturais, sustentabilidade ecológica do hábitat). (LEFF, 2002, p. 149).
\end{abstract}

Apesar do conceito de qualidade de vida e qualidade ambiental se interligarem, estes conceitos não podem ser considerados como sinônimos. Segundo Guimarães (2005) o conceito de qualidade ambiental deve ser analisado de forma mais ampla em razão da complexidade dos sistemas responsáveis pela vida no planeta.

\begin{abstract}
Qualidade ambiental é um conceito mais amplo, tendo em vista que o meio ambiente, consideradas as suas dimensões materiais e imateriais, pode ser analisado como substrato e mediador de todas as formas de vida, permitindo o desenvolvimento dos processos vitais, das relações ecológicas, da evolução dos ecossistemas naturais e construídos do planeta, da construção/destruição, ou seja, da evolução das paisagens externas e internas. (GUIMARÃES, 2005, p. 21).
\end{abstract}

Complementando a discussão, Macedo (1995, p. 17) conceitua qualidade ambiental a partir dos "mecanismos de adaptação" e "auto-superação" dos ecossistemas ${ }^{1}$, onde afirma com "base na teoria sistêmica da evolução" que a qualidade ambiental é oriunda da "ação simultânea da necessidade e do acaso".

\begin{abstract}
Qualidade ambiental de um ecossistema expressa as condições e os requisitos básicos que ele detém, de natureza física, química, biológica, social, econômica, tecnológica, cultural e política, de modo a que os fatores ambientais que o constituem em qualquer instante, [...] possam exercer efetivamente as relações ambientais que lhes são naturalmente afetas, necessárias à manutenção de sua dinâmica e, por conseguinte, a dinâmica do ecossistema de que fazem parte, bem como, [...] detenham a capacidade completa de auto-superação, que os permita desenvolver novas estruturas e promover, aleatoriamente, desdobramentos ordenados da complexidade do ecossistema. (MACEDO, 1995, p.17)
\end{abstract}

Para Guimarães (2005) o conceito de qualidade ambiental incorpora as "dimensões materiais e imateriais" do meio ambiente ${ }^{2}$, podendo ser avaliado como "substrato e mediador de todas as

\footnotetext{
1 “O termo ecossistema é constituído por qualquer unidade que inclui a totalidade dos organismos em uma área interagindo com o meio ambiente físico, de modo que um fluxo de energia promove a permuta de materiais entre os componentes vivos e abióticos. Nesta cadeia de interação pode-se analisar o fluxo de nutrientes, a produtividade, a dinâmica da população, a sucessão, a diversidade, a estabilidade e o grau das modificações" (CHRISFOLETTI, 1995, p. 336, grifo do autor).

2 "O termo ambiente vem sendo empregado de forma generalizada e ampla, pois possibilita ser utilizado desde a escala mundial até a microescala pontual. Pode-se falar de ambientes continentais, oceânicos, lacustres, dos ambientes das plantas, dos animais e dos homens, do ambiente urbano e do rural, do ambiente cultural, social e do
} 
formas de vida". Nessa abordagem, eclodem os processos vitais "das relações ecológicas, da evolução dos ecossistemas naturais e construídos do planeta, da construção/destruição", o que possibilita à evolução das paisagens, seja no âmbito externo e interno. Christofoletti (1995, p. 337) complementa afirmando que as interferências antrópicas influem nas "características e nos fluxos de materiais e energias, modificando o equilíbrio 'natural' dos ecossistemas e geossistemas"

\section{A CONSTRUÇÃO DO CONCEITO DE QUALIDADE AMBIENTAL URBANA}

Jesus e Braga (2005, p. 208) afirmam que qualidade ambiental "[...] está intimamente ligada à qualidade de vida, pois vida e meio ambiente são inseparáveis. Há uma interação e um equilíbrio entre ambos que varia de escala em tempo e lugar".

Essa interação entre qualidade de vida e qualidade ambiental apontada por Jesus e Braga (2005), passa a ser mais evidenciada ao se restringir o objeto de estudo à qualidade ambiental urbana. Por esta razão, depara-se com a problemática em determinar o que é qualidade de vida e o que vem a ser qualidade ambiental urbana, em razão da dificuldade de se estabelecer onde começa uma e onde termina a outra.

Segundo Ribeiro e Vargas (2004, p. 13-15) a definição de qualidade ambiental urbana "envolve uma série de questões de cunho subjetivo, político e ético", bem como está ligada a dois outros conceitos: ao "ecossistema urbano" ${ }^{4}$ e ao conceito de "qualidade de vida", bem como apontam alguns fatores que interferem na definição da qualidade ambiental urbana (QUADRO 01).

trabalho. A palavra é a mesma, mas diferentes são os significados e a expressividade. Comumente também se fala do ambiente familiar e do ambiente de oportunidades. Em conseqüência desse uso irrestrito, o termo perde respeitabilidade analítica e se constitui numa designação para tudo e para todos." (CHRISFOLETTI, 1995, p. 336, grifo do autor).

3 "Os sistemas ambientais físicos, também designados geossistemas, representam a organização espacial resultante da interação dos elementos componentes físicos da natureza (clima, topografia, rocha, água, vegetação, animais, solo)" (CHRISFOLETTI, 1995, p. 337, grifo do autor).

${ }^{4}$ Para Ribeiro e Vargas (2004, p. 15), "o ecossistema urbano é um sistema complexo cujos elementos e funções estão estreitamente correlacionados. Como nos ecossistemas naturais, um ecossistema urbano transforma energia (trabalho humano, capital, energia fóssil etc.) e materiais (madeira, ferro, areia, rocha, informações etc.) em produtos, que são consumidos e exportados, e em resíduos (Brugmann and Hersh apud Roseland 1992). Existem sempre uma associação entre o meio natural e o construído, no qual se imprime a marca da criatividade humana e das inovações culturais que humanizam o meio natural (Regales, 1997). Para Brugmann (1992), o ecossistema urbano caracteriza-se pela forte presença da atividade humana transformadora o ambiente natural, pela produção e consumo constantes e pelo estabelecimento de fluxos intensos de toda ordem (fluxos de pessoas, de energia, recursos econômicos e relações sociais)". 


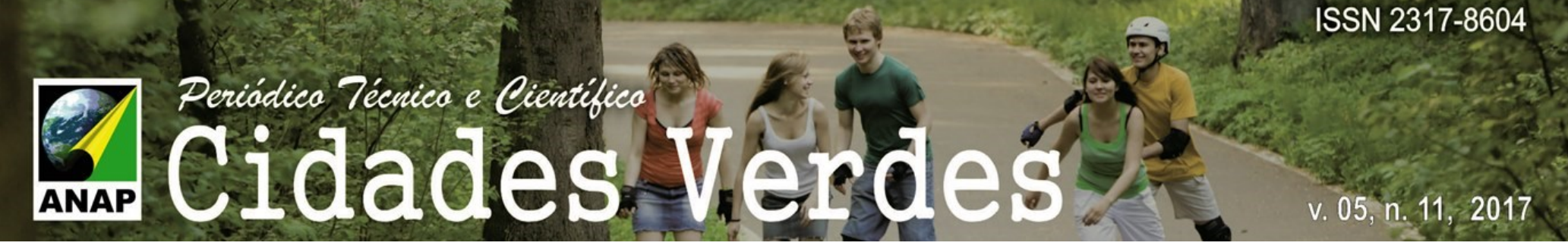

Quadro 01 - Componentes da Qualidade Ambiental Urbana

\begin{tabular}{|c|l|}
\hline & $\begin{array}{l}\text { Bem-estar: vegetação, espaço abertos, tranqüilidade } \\
\text { Acessibilidade: sistema viário, transporte } \\
\text { Desenho Urbano: elementos visuais, monotonia, informação } \\
\text { Referenciais: orientação, história, marcos } \\
\text { Uso/ocupação do Solo: densidade, conflito de usos, segregação }\end{array}$ \\
\hline Biológicas & $\begin{array}{l}\text { Saúde Física: saneamento, insolação, ruídos, qualidade do ar } \\
\text { Saúde Mental: estresse, congestionamentos, solidão, reclamações } \\
\text { Segurança: trânsito, edificações, marginalidade }\end{array}$ \\
\hline Sociais & $\begin{array}{l}\text { Organização: comunitária, de classe, associações } \\
\text { Cealização Pessoal: amizade, afeto, reconhecimento } \\
\text { Contatos: encontros, privacidade, solidariedade } \\
\text { Realização profissional: mobilidade, oportunidades } \\
\text { Acesso e opções: moradia, trabalho, serviços urbanos, transporte }\end{array}$ \\
\hline $\begin{array}{l}\text { Oportunidade: emprego, trabalho, negócios } \\
\text { Problemas da aglomeração: trânsito, custo de vida, competição } \\
\text { Diversidade: escolhas }\end{array}$ \\
\hline
\end{tabular}

Fonte: RIBEIRO; VARGAS, 2004, p. 18.

Considerando a contribuição de Ribeiro e Vargas, bem como dos demais autores supracitados, pode-se concluir que as intervenções antrópicas no meio possam ser determinantes na construção do conceito de qualidade ambiental urbana.

As cidades apresentam uma dinâmica própria onde os homens necessitam dos recursos naturais para a produção de bens e serviços, bem como para sua sobrevivência. Entretanto os processos produtivos estão atrelados ao consumismo voraz, enquanto uma interface do capitalismo. 

objetividade ou subjetividade, na produção, reprodução, degradação, destruição do ambiente urbano o qual está inserido.

\section{CONSIDERAÇÕES FINAIS}

No contexto urbano, não há como considerar qualidade ambiental urbana como sinônima de qualidade ambiental e excluir deste recorte analítico a qualidade de vida, pois está ultima é imprescindível ao bem-estar da sociedade, visto que decorre da satisfação das necessidades humanas no contexto sociocultural e econômico em que o homem está inserido.

Tendo em vista que as cidades incorporam as dimensões materiais e imateriais do meio ambiente no seu processo de produção, independente de tempo e escala, onde bens e serviços podem ser considerados como indicadores da qualidade ambiental urbana, o homem ainda se apresenta com agente produtor deste processo.

Nesta rápida abordagem, pode-se concluir que a qualidade de vida esta necessariamente atrelada aos valores produzidos pelos processos mediáticos, onde o consumismo voraz dita regras e comportamento em detrimento da qualidade ambiental.

Desse modo, podemos imaginar que os assentamentos humanos só poderão alcançar a qualidade ambiental urbana, quando houver um equilíbrio entre a ordem econômica e o contexto sociocultural, de modo a equacionar a apropriação dos bens ambientais.

\section{REFERÊNCIAS}

BRAGA, Roberto. Qualidade de vida urbana e cidadania. Território \& Cidadania. Rio Claro, SP, ano II, no 2, jun-dez, 2002. Disponível em:

<http://www.rc.unesp.br/igce/planejamento/territorioecidadania/Artigos/Braga\%203.htm> 09 jan. 2009.

CHRISFOLETTI, Antônio. A geografia física no estudo das mudanças ambientais. In. CHRISFOLETTI, Antônio; BECKER, Bertha k.; VIDOVICH, Fany R. da; GEIGER, Pedro P.. Geografia e meio ambiente no Brasil. São Paulo-Rio de Janeiro: Ed. HUCITEC, 1995, p. 334-370.

CUTTER, S. L. 1985. Rating Places - A Geographer's View on Quality of life. Pennsylvania, American Geographer's Association. Resource Publication in Geography.

GUIMARÃES, Solange T. de Lima. Nas Trilhas da Qualidade: algumas idéias, visões e conceitos sobre qualidade ambiental e de vida..., Revista GEOSUL, UFSC, Florianópolis, n.40, p. 7-26, jul./dez. 2005, Disponível em: <http://www.cultiva.org.br/pdf/qualidade_ambiental_e_da_vida.pdf > Acesso em: 15 jan. 2009.

LEFF, Enrique. Saber Ambiental: sustentabilidade, racionalidade, complexidade, poder. 2.ed. Petrópolis: Editora Vozes, 2001.

. Epistemologia ambiental. Tradução de Sandra Valenzuela. 3. ed. São Paulo: Cortez, 2002.

JESUS, Silva Cristina de; BRAGA, Roberto. ANÁLISE ESPACIAL DAS ÁREAS VERDES URBANAS DA ESTÂNCIA DE ÁGUAS DE SÃO PEDRO - SP. Caminhos da Geografia. V. 16, ano 6, p. 206 - 224, out. 2005, ISSN: 


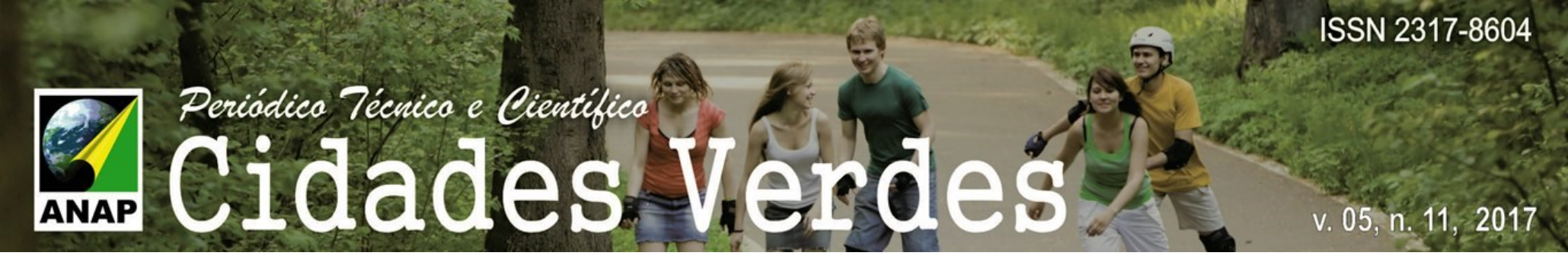

1678-6343. Disponível em: <http://www.ig.ufu.br/revista/volume16/artigo19_vol16.pdf> Acesso em: 09 jan. 2009.

MACEDO, Ricardo Kohn de. A importância da avaliação ambiental. In. TAUK, Sâmia Maria (org). Análise Ambiental: uma visão multidisciplinar. 2. ed. rev. e amp. São Paulo: EDUSP, 1995, p. 13 - 31

RIBEIRO, Helena; VARGAS, Heliana Comin. Qualidade Ambiental Urbana: Ensaios de uma definição. In. (Org). Novos Instrumentos de Gestão Ambiental Urbana. São Paulo: Edusp, 2004, 146 p.

SANTOS, L. D.; MARTINS I.. A qualidade da vida urbana. O caso da cidade do Porto. Universidade do Porto. Disponível em: <www.fep.up.pt/investigacao/workingpapers/wp116.pdf> Acesso em: 10 out. 2004.

THE WHOQOL GROUP. The World Health Organization quality of life assessment (WHOQOL): position paper from the World Health Organization. Soc Sci Méd; 41:1403-10. 1995. 